Article

\title{
Free Fatty Acids' Level and Nutrition in Critically Ill Patients and Association with Outcomes: A Prospective Sub-Study of PermiT Trial
}

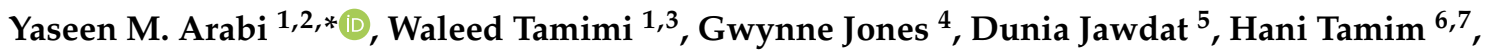 \\ Hasan M. Al-Dorzi 1,2 (D), Musharaf Sadat 1,2, Lara Afesh ${ }^{7}$, Maram Sakhija 1,2 and \\ Abdulaziz Al-Dawood 1,2 \\ 1 College of Medicine, King Saud bin Abdulaziz University for Health Sciences, King Abdullah International \\ Medical Research Center, Riyadh 11426, Saudi Arabia; TamimiW@NGHA.MED.SA (W.T.); \\ aldorziha@NGHA.MED.SA (H.M.A.-D.); sadatmu@ngha.med.sa (M.S.); SakkijhaM@NGHA.MED.SA (M.S.); \\ dawooda@ngha.med.sa (A.A.-D.) \\ 2 Intensive Care Department, King Abdulaziz Medical City, Riyadh 11426, Saudi Arabia \\ 3 Department of Clinical Laboratory, King Abdulaziz Medical City, Riyadh 11426, Saudi Arabia \\ 4 Department of Medicine, Division of Critical Care Medicine, University of Ottawa, Ottawa Hospital \\ Research Institute, Ottawa KIH 8L6, Canada; GJones@ottawahospital.on.ca \\ 5 College of Medicine, King Saud bin Abdulaziz University for Health Sciences, Cord Blood Bank, \\ King Abdullah International Medical Research Center, Riyadh 11426, Saudi Arabia; \\ JawdatD@NGHA.MED.SA \\ 6 Department of Internal Medicine, American University of Beirut-Medical Center, Beirut 110-236, Lebanon; \\ hani_t@hotmail.com \\ 7 King Abdullah International Medical Research Center, Riyadh 11426, Saudi Arabia; Afeshla@ngha.med.sa \\ * Correspondence: yaseenarabi@yahoo.com; Tel.: +966-11-8011111
}

Received: 27 January 2019; Accepted: 5 February 2019; Published: 13 February 2019

Abstract: Objectives: The objectives of this study were to evaluate the clinical and nutritional correlates of high free fatty acids (FFAs) level in critically ill patients and the association with outcomes, and to study the effect of short-term caloric restriction (permissive underfeeding) on FFAs level during critical illness. Patients/Method: In this pre-planned sub-study of the PermiT (Permissive Underfeeding vs. Target Enteral Feeding in Adult Critically Ill Patients) trial, we included critically ill patients who were expected to stay for $\geq 14$ days in the intensive care unit. We measured FFAs level on day 1, 3, 5, 7, and 14 of enrollment. Of 70 enrolled patients, $23(32.8 \%)$ patients had high FFAs level (baseline FFAs level $>0.45 \mathrm{mmol} / \mathrm{L}$ in females and $>0.6 \mathrm{mmol} / \mathrm{L}$ in males). Results: Patients with high FFAs level were significantly older and more likely to be females and diabetics and they had lower ratio of partial pressure of oxygen to the fraction of inspired oxygen, higher creatinine, and higher total cholesterol levels than those with normal FFAs level. During the study period, patients with high FFAs level had higher blood glucose and required more insulin. On multivariable logistic regression analysis, the predictors of high baseline FFAs level were diabetes (adjusted odds ratio (aOR): 5.36 ; 95\% confidence interval $(\mathrm{CI}): 1.56,18.43, p=0.008$ ) and baseline cholesterol level (aOR, 4.29; 95\% CI: 11.64, 11.19, $p=0.003$ ). Serial levels of FFAs did not differ with time between permissive underfeeding and standard feeding groups. FFAs level was not associated with 90-day mortality (aOR: 0.49; 95\% CI: 0.09, 2.60, $p=0.40$ ). Conclusion: We conclude that high FFAs level in critically ill patients is associated with features of metabolic syndrome and is not affected by short-term permissive underfeeding.

Keywords: critical illness; nonesterified fatty acids; caloric restriction; insulin resistance; metabolic syndrome 


\section{Introduction}

Fatty acids are a major source of fuel in the body and play an important role in cell signaling [1,2]. Free fatty acids (FFAs) are nonesterified fatty acids that are released by the hydrolysis of triglycerides (triglyceride molecule is composed of three fatty acid molecules bound to glycerol) within the adipose tissue by lipoprotein lipase. They circulate in the blood protein-bound, serving as an energy source for tissues [1,3]. Chronically elevated FFAs level has been observed in obese people and in diabetic patients and is associated with insulin resistance and with sudden death in middle-aged men without known ischemic heart disease $[1,3,4]$.

Acutely, FFAs level is often increased during critical illness and may contribute to organ dysfunction. Critical illness is characterized by hypercatabolic state and by a change in the contribution of the endogenous protein, fat, and carbohydrate sources to oxidative fuel [5]. Lipolysis is accelerated by the high catecholamine and other stress hormone milieu leading to increased release of FFAs from adipocytes, thus, increasing FFAs level [6]. Insulin resistance during critical illness impairs the use of FFAs for energy, and, thus, contributes to increased FFAs level [7]. Heparin given during critical illness may also increase FFAs level by activating lipoprotein lipase [8]. FFAs may have toxic effects by increasing reactive oxygen species leading to cell death and necrosis [9] and by depressing the immune cell function [10]. In addition, FFAs potentiate insulin resistance and impair glucose metabolism by inhibiting glucose oxidation and by stimulating protein kinase C [1,10]. In an acute setting, elevated FFAs level has been associated with the development of acute lung injury in at-risk patients with sepsis, trauma, and pancreatitis and after on-pump coronary artery bypass grafting [8,11,12].

Can FFAs level in critically ill patients be modulated by short-term caloric restriction (permissive underfeeding)? Normally, serum FFAs level increases during fasting and exercise and after a fatty meal. FFAs level goes down postprandially due to the anti-lipolytic effect of insulin that is released after carbohydrate intake [13]. On the other hand, caloric restriction and weight loss lead to a lowering of FFAs level and can attenuate FFAs-induced hepatic insulin resistance in obese healthy patients [14-16]. However, the effect of caloric restriction on serum FFAs level has not been investigated in critically ill patients. The aims of this study were (1) to evaluate the clinical and nutritional correlates of high FFAs level in critically ill patients and the association with outcomes, and (2) study the effect of short-term caloric restriction (permissive underfeeding) on FFAs level during critical illness.

\section{Materials and Methods}

\subsection{Patients}

This is a pre-planned sub-study of the PermiT [17] (Permissive Underfeeding vs. Target Enteral Feeding in Adult Critically Ill Patients-ISRCTN68144998) trial, in which critically ill patients were randomized to permissive underfeeding (40-60\% of calculated caloric requirements) or standard feeding (70-100\%) for up to 14 days while maintaining similar protein intake in both groups. The trial found no difference in the primary endpoint of 90-day mortality. In this sub-study which was separately funded by King Abdulaziz City for Science and Technology (KACST), Riyadh, Saudi Arabia (Grant Number-AT 32-25 KACST), we enrolled consecutive patients from the PermiT trial at King Abdulaziz Medical City, Riyadh, Saudi Arabia between September 2012 and September 2014 who were expected to stay $\geq 14$ days in the intensive care unit as judged by their primary team. A separate informed consent was obtained for participation in this sub-study. The study was approved by the Institutional Board Review of the Ministry of the National Guard Health Affairs, Riyadh, Saudi Arabia. Blood was collected at the time of enrollment (baseline or study day 1 ) within $48 \mathrm{~h}$ of ICU admission and on days $3,5,7$, and 14 . Serum was prepared from the blood samples by centrifugation at $4{ }^{\circ} \mathrm{C}$ at $1600 \mathrm{~g}$ for $20 \mathrm{~min}$ and divided into aliquots. These aliquots were stored immediately in a designated freezing area at $-70{ }^{\circ} \mathrm{C}$ to be analyzed once the sample size was completed. The samples were analyzed blindly, and then the sample codes were broken. 


\subsection{Free Fatty Acids Measurement}

The measurement of FFAs was performed in Bioscientia reference laboratory in Germany using an in-vitro enzymatic calorimetric assay with Wako-NEFA-HR (2) reagent (Wako-chemicals, Neuss, Germany) [18]. In this method, FFAs with the coexistence coenzyme A (CoA) and adenosine-5'-triphosphate (ATP) disodium salt were converted to Acyl-CoA, adenosine monophosphate (AMP) and pyrophosphoric acid by the action of Acyl-CoA synthetase (ACS). The Acyl-CoA was oxidized yielding 2,3-trans-enoyl-CoA and hydrogen peroxide $\left(\mathrm{H}_{2} \mathrm{O}_{2}\right)$ by the action of acyl-CoA oxidase. In the presence of peroxidase, $\mathrm{H}_{2} \mathrm{O}_{2}$ yielded a blue-purple pigment by quantitative oxidation condensation with 3-Methyl-N-Ethyl-N-( $\beta$-Hydroxyethyl)-Aniline (MEHA) and 4 -aminoantipyrine (4AA). FFAs level was obtained by measuring absorbance at the blue and purple color at wavelengths of $546 \mathrm{~nm}$ and $660 \mathrm{~nm}$.

The normal fasting serum FFAs level is 0.1 to $0.45 \mathrm{mmol} / \mathrm{L}$ for females and 0.1 to $0.6 \mathrm{mmol} / \mathrm{L}$ for males. However, FFAs level in the critically ill is poorly studied. In the current study, patients with FFAs more than $0.45 \mathrm{mmol} / \mathrm{L}$ in females and $0.6 \mathrm{mmol} / \mathrm{L}$ in males were considered to have high FFAs level; otherwise FFAs level was considered normal.

\subsection{Data Collection}

Baseline data included demographics, Acute Physiology and Chronic Health Evaluation Scores (APACHE) II [19], presence of sepsis upon admission, Sequential Organ Failure Assessment (SOFA) score [20], the ratio of partial pressure of arterial oxygen to the fraction of inspired oxygen $\left(\mathrm{PaO}_{2}: \mathrm{FiO}_{2}\right)$, Glasgow coma scale and various laboratory results (baseline blood glucose, hemoglobin, international normalized ratio(INR), platelets, bilirubin, creatinine, C-reactive protein, albumin, pre-albumin, transferrin, 24-h urinary urea nitrogen excretion, and nitrogen balance). For the intervention period, which lasted for up to 14 days, we collected daily nutritional data (feeding formula and calories from enteral feeds, propofol, intravenous dextrose, and parenteral nutrition), insulin dose for hyperglycemia management, daily blood glucose, and use of certain medications, such as aspirin, beta-blockers and statins. We noted the daily carbohydrate, fat, and protein calories from enteral and parenteral sources and then calculated the total fat-to-carbohydrate ratio by dividing fat calories by carbohydrate calories.

The outcomes evaluated in this study were 28-, 90-, and 180-day all-cause mortality. Other outcomes included hospital and ICU mortality, incident renal replacement therapy, ICU-associated infections [21], ICU and hospital length of stay (LOS), and mechanical ventilation duration. In addition, ICU-free days, renal replacement therapy-free days, and ventilator-free days were also calculated.

\subsection{Statistical Analysis}

We reported categorical variables as frequencies with percentages and continuous variables as medians with quartile 1 and $3(\mathrm{Q} 1, \mathrm{Q} 3)$. We compared categorical variables using chi-square or Fisher's exact test and continuous variables using Mann-Whitney U test. We examined Pearson correlation among the following baseline variables FFAs level, age, body mass index, total cholesterol, high-density lipoprotein (HDL) cholesterol, low-density lipoprotein (LDL) cholesterol, non-HDL cholesterol, triglycerides, glucose, and hemoglobin A1c. In addition, multivariable logistic regression analysis was performed to assess the predictors of high FFAs level. We entered in the model a priori decided baseline variables that were of clinical interest and/or had significant association with high FFAs level by univariable analysis $(p \leq 0.05)$ which included age, gender, body mass index (BMI), APACHE II, diabetes, triglycerides, LDL cholesterol, HDL cholesterol, medical admissions (vs. non-medical admissions), and randomization (permissive vs. standard feeding). We also carried out a linear mixed model to test whether FFAs level is affected over time with permissive underfeeding compared to standard feeding. We carried out logistic and linear regression models to examine the association between FFAs level and outcomes adjusting for age, gender, BMI, APACHE II, diabetes, triglycerides, LDL cholesterol, HDL cholesterol, non-HDL cholesterol, and medical admissions (vs. non-medical 
admissions). A two-tailed $p$ value $<0.05$ was considered statistically significant. The results were expressed as adjusted odds ratio (aOR) or parameter estimate with $95 \%$ confidence intervals $(95 \% \mathrm{CI})$. All statistical analyses were performed using SAS version 9.2 (SAS Institute, Cary, NC, USA).

\section{Results}

\subsection{Characteristics of Patients}

Of the 70 patients included in the study (Figure S1), 23 (32.8\%) had high FFAs level (median $0.74 \mathrm{mmol} / \mathrm{L}(\mathrm{Q} 1, \mathrm{Q} 3: 0.63,1.06)$ and $47(67.1 \%)$ had normal FFAs level $(0.34 \mathrm{mmol} / \mathrm{L}(0.22,0.45)))$. Patients with high FFAs level were significantly older, more likely to be females and diabetic, had higher HgbA1c, creatinine and non-HDL and LDL cholesterol levels, and had lower $\mathrm{PaO}_{2}: \mathrm{FiO}_{2}$ ratio compared with patients with normal FFAs (Table 1). There were significant correlations between FFAs level and total cholesterol $(r=0.45, p=0.0001)$, non-HDL cholesterol $(\mathrm{r}=0.38, p=0.002)$, HDL cholesterol $(r=0.30, p=0.01)$ and LDL cholesterol $(r=0.43, p=0.0003)$, and age $(r=0.40, p=0.0006)$ (Table S1).

Table 2 shows the nutritional data during the study period and the trial co-interventions. The total daily caloric intake was $1065.6 \mathrm{kcal}(\mathrm{Q} 1, \mathrm{Q} 3:$ 785.0, 1496.1) in patients with high FFAs level and $1071.0 \mathrm{kcal}(\mathrm{Q} 1, \mathrm{Q} 3:$ 810.0, 1368.5) in patients with normal FFAs level $(p=0.73)$. The median calories from propofol were only $17.3 \mathrm{kcal}(\mathrm{Q} 1, \mathrm{Q} 3: 0.0,102.6)$ in patients with high FFAs level and 70.3 (Q1, Q3: $19.1,134.2)$ in patients with normal FFAs level $(p=0.06)$. This corresponded to the following doses of propofol; $1.2 \mathrm{mcg} / \mathrm{kg} / \mathrm{min}$ (Q1, Q3: 0.0, 9.0) in patients with high FFAs level and $5.2 \mathrm{mcg} / \mathrm{kg} / \mathrm{min}$ (Q1, Q3: $1.4,11.2)$ in patients with normal FFAs level $(p=0.06)$. The daily protein intake was $55.4 \mathrm{~g}(\mathrm{Q} 1$, Q3: 44.2, 66.4) in patients with high FFAs level and $61.9 \mathrm{~g}(\mathrm{Q} 1, \mathrm{Q} 3: 42.8,77.1)$ in patients with normal FFAs level $(p=0.37)$. The baseline blood glucose was similar in the two groups; however, during the study period, the glucose level was significantly higher in patients with high FFAs level compared to patients with normal FFAs level $(9.5 \mathrm{mmol} / \mathrm{L}(\mathrm{Q} 1, \mathrm{Q} 3:$ 7.6, 11.9) compared to $7.7 \mathrm{mmol} / \mathrm{L}$ (Q1, Q3: $6.5,10.3) p=0.05)$ with higher use of insulin (18.9 units per day (Q1, Q3: 3.8, 37.5) compared to 0.0 units per day $(\mathrm{Q} 1, \mathrm{Q} 3: 0.0,14.9) p=0.003)$. Additionally, more patients in the high FFAs level received disease-specific formulae, renal replacement therapy, aspirin and statins during ICU stay. 
Table 1. Baseline characteristics of patients with high and normal free fatty acids (FFAs) level.

\begin{tabular}{|c|c|c|c|}
\hline Variable & $\begin{array}{l}\text { High FFAs Level * } \\
\quad n=23\end{array}$ & $\begin{array}{c}\text { Normal FFAs Level * } \\
\quad n=47\end{array}$ & $p$-Value \\
\hline Age (years), median (Q1, Q3) & $65(30.9,70.6)$ & $30.2(24.4,61.1)$ & 0.006 \\
\hline Female sex, $n(\%)$ & $10(45.5)$ & $6(13.0)$ & 0.003 \\
\hline Height $(\mathrm{cm})$, median $(\mathrm{Q} 1, \mathrm{Q} 3)$ & $164(150,168)$ & $170(165,173)$ & 0.002 \\
\hline Weight $(\mathrm{kg})$, median $(\mathrm{Q} 1, \mathrm{Q} 3)$ & $80(56,93)$ & $75(60,96)$ & 0.84 \\
\hline Body mass index $\left(\mathrm{kg} / \mathrm{m}^{2}\right)$, median $(\mathrm{Q} 1, \mathrm{Q} 3)$ & $27.9(25.3,35.1)$ & $27.3(21.2,32.5)$ & 0.13 \\
\hline Diabetes, $n(\%)$ & $14(63.6)$ & $11(23.9)$ & 0.002 \\
\hline \multicolumn{4}{|l|}{ Admission category, $n(\%)$} \\
\hline Medical & $17(77.3)$ & $19(41.3)$ & \multirow{3}{*}{0.26} \\
\hline Surgical & $0(0.00)$ & $4(8.7)$ & \\
\hline Post-operative trauma & $5(22.7)$ & $23(50.0)$ & \\
\hline Patients on renal replacement therapy, $n(\%)$ & $0(0.00)$ & $3(6.5)$ & 0.22 \\
\hline APACHE II, median (Q1, Q3) & $21(15,27)$ & $18(14,23)$ & 0.17 \\
\hline Mechanical ventilation, $n(\%)$ & $22(100)$ & $44(96.7)$ & 0.32 \\
\hline Sepsis at admission, $n(\%)$ & $5(22.7)$ & $8(17.4)$ & 0.60 \\
\hline SOFA Score Day 1, median (Q1, Q3) & $12(8,13)$ & $10(8,12)$ & 0.05 \\
\hline $\mathrm{PaO}_{2}: \mathrm{FiO}_{2}$ ratio, median $(\mathrm{Q} 1, \mathrm{Q3})$ & $115(73,171)$ & $200(114,311)$ & 0.02 \\
\hline Glasgow coma scale, median (Q1, Q3) & $4(3,6)$ & $3(3,5)$ & 0.11 \\
\hline Vasopressor, $n(\%)$ & $14(63.6)$ & $29(63.0)$ & 0.96 \\
\hline Baseline blood glucose (mmol/L), median (Q1, Q3) & $10.8(7.9,14.0)$ & $9.0(7.7,12.5)$ & 0.50 \\
\hline Hemoglobin $(\mathrm{g} / \mathrm{L})$, median $(\mathrm{Q} 1, \mathrm{Q} 3)$ & $110.0(88.0,125.0)$ & $109.5(93.0,124.0)$ & 0.79 \\
\hline INR, median (Q1, Q3) & $1.2(1.0,1.3)$ & $1.2(1.1,1.3)$ & 0.89 \\
\hline Platelets $\left(10^{9} / \mathrm{L}\right)$, median $(\mathrm{Q} 1, \mathrm{Q} 3)$ & $177(123,264)$ & $163(117,241)$ & 0.90 \\
\hline Bilirubin $(\mu \mathrm{mol} / \mathrm{L})$, median $(\mathrm{Q} 1, \mathrm{Q} 3)$ & $13.2(6.9,25.3)$ & $14.1(8.7,27.1)$ & 0.45 \\
\hline Creatinine $(\mu \mathrm{mol} / \mathrm{L})$, median $(\mathrm{Q} 1, \mathrm{Q} 3)$ & $118(81,253)$ & $77(67,96)$ & 0.001 \\
\hline C-reactive protein (mg/liter), median (Q1, Q3) & $131.0(47.6,160.0)$ & $149.0(108.0,207.0)$ & 0.07 \\
\hline \multicolumn{4}{|l|}{ Serum lipid profile (mmol/liter), median (Q1, Q3) } \\
\hline Triglycerides & $1.2(0.9,2.2)$ & $1.2(0.9,1.8)$ & 0.48 \\
\hline Cholesterol & $2.9(2.5,3.3)$ & $2.2(1.8,2.7)$ & 0.001 \\
\hline Non-HDL cholesterol & $2.2(1.8,3.1)$ & $1.7(1.4,2.1)$ & 0.003 \\
\hline HDL cholesterol & $0.6(0.4,0.8)$ & $0.5(0.4,0.7)$ & 0.33 \\
\hline LDL cholesterol & $1.3(0.9,1.7)$ & $0.9(0.7,1.2)$ & 0.01 \\
\hline Albumin $(\mathrm{g} / \mathrm{L})$, median $(\mathrm{Q} 1, \mathrm{Q} 3)$ & $29(28,31)$ & $27(23,320$ & 0.15 \\
\hline Pre-albumin $(\mathrm{g} / \mathrm{L})$, median (Q1, Q3) & $0.10(0.07,0.12)$ & $0.12(0.09,0.14)$ & 0.11 \\
\hline Transferrin $(\mathrm{g} / \mathrm{L})$, median $(\mathrm{Q} 1, \mathrm{Q} 3)$ & $1.3(1.0,1.3)$ & $1.2(1.0,1.5)$ & 0.67 \\
\hline Hemoglobin A1C (\%), median (Q1, Q3) & $6.0(5.8,7.3)$ & $5.5(5.4,6.2)$ & 0.04 \\
\hline 24-h urinary nitrogen excretion (g/day), median (Q1, Q3) & $4.8(2.4,7.0)$ & $7.2(5.1,11.4)$ & 0.007 \\
\hline Nitrogen balance (g/day) & $-2.1(-4.3,-0.1)$ & $-6.9(-10.1,-2.4)$ & 0.003 \\
\hline Minute ventilation (L), median (Q1, Q3) & $9.4(8.7,10.6)$ & $10.3(7.9,11.5)$ & 0.56 \\
\hline Maximum temperature $\left({ }^{\circ} \mathrm{C}\right)$, median $(\mathrm{Q} 1, \mathrm{Q} 3)$ & $37.1(36.5,37.6)$ & $37.1(36.6,37.7)$ & 0.75 \\
\hline
\end{tabular}

BMI: body mass index; APACHE II: Acute Physiology and Chronic Health Evaluation II; INR: International normalized ratio; SOFA: Sequential Organ Failure Assessment; PaO 2 : FIO 2 ratio: the ratio of partial pressure of oxygen to the fraction of inspired oxygen; Non-HDL cholesterol: Total cholesterol-HDL, HDL: High density lipoproteins; LDL: Low density lipoproteins; The denominators for all percentages is the $\mathrm{N}$ for each column. Continuous variables are represented as median (quartile 1 and quartile 3 ). ${ }^{*}$ FFAs normal range: 0.1 to 0.45 mmol/L (females); 0.1 to $0.6 \mathrm{mmol} / \mathrm{L}$ (males). Q1: first quartile, Q3: third quartile. 
Table 2. Daily caloric intake, protein intake, insulin and glucose data in patients with high and normal free fatty acids (FFAs) level.

\begin{tabular}{|c|c|c|c|}
\hline Variable & $\begin{array}{c}\text { High FFAs Level } \\
n=23\end{array}$ & $\begin{array}{c}\text { Normal FFAs Level } \\
n=47\end{array}$ & $p$-Value \\
\hline Calculated caloric requirement (kcal/day), median (Q1, Q3) & $1729(1371,2031)$ & $1909(1588,2119)$ & 0.12 \\
\hline No. of kilocalories, median (Q1, Q3) & $1065.6(785.0,1496.1)$ & $1071(810.0,1368.5)$ & 0.73 \\
\hline Percent of requirement, median (Q1, Q3) & $61.5(49.3,84.2)$ & $55.8(50.2,74.9)$ & 0.64 \\
\hline \multicolumn{4}{|l|}{$\begin{array}{c}\text { Daily caloric intake for the intervention duration-Permissive } \\
\text { underfeeding }\end{array}$} \\
\hline$n(\%)$ & $12(52.2)$ & $26(55.3)$ & 0.80 \\
\hline No. of kilocalories, median (Q1, Q3) & $838.7(622.4,1028.1)$ & $992.6(792.1,1109.7)$ & 0.12 \\
\hline Percent of requirement, median (Q1, Q3) & $53.7(42.5,60.3)$ & $53.1(48.0,57.0)$ & 0.94 \\
\hline \multicolumn{4}{|l|}{ Daily caloric intake for the intervention duration-Standard feeding } \\
\hline$n(\%)$ & $11(47.8)$ & $21(44.7)$ & 0.80 \\
\hline No. of kilocalories, median (Q1, Q3) & $1496.1(1136.1,1708.3)$ & $1355.4(1042.4,1626.6)$ & 0.63 \\
\hline Percent of requirement, median (Q1, Q3) & $84.2(63.8,91.1)$ & $74.9(55.7,88.5)$ & 0.61 \\
\hline \multicolumn{4}{|l|}{$\begin{array}{c}\text { Caloric source for the intervention duration-All patients (kcal / day), } \\
\text { median }(\mathrm{Q} 1, \mathrm{Q} 3)\end{array}$} \\
\hline Enteral & $1027.2(709.3,1393.5)$ & $997.2(732.1,1323.4)$ & 0.99 \\
\hline Propofol & $17.3(0.0,102.6)$ & $70.3(19.1,134.2)$ & 0.06 \\
\hline Intravenous dextrose & $6.1(0.0,22.3)$ & $0.0(0.0,24.4)$ & 0.76 \\
\hline Total parenteral nutrition & $0(0,0)$ & $0(0,0)$ & 1.00 \\
\hline Calculated protein requirement $(\mathrm{g} /$ day), median $(\mathrm{Q} 1, \mathrm{Q} 3)$ & $72(60,85)$ & $88(72,99)$ & 0.03 \\
\hline \multicolumn{4}{|l|}{ Daily protein intake for the intervention duration, median $(\mathrm{Q} 1, \mathrm{Q} 3)$} \\
\hline No. of grams & $55.4(44.2,66.4)$ & $61.9(42.8,77.1)$ & 0.37 \\
\hline Percent of requirement & $88.1(60.6,88.8)$ & $76.5(59.6,87.7)$ & 0.62 \\
\hline Fat-to-carbohydrate ratio, median (Q1, Q3) & $1.3(0.6,1.7)$ & $0.7(0.6,1.1)$ & 0.06 \\
\hline Duration of intervention (days), median (Q1, Q3) & $12(6,14)$ & $11(9,14)$ & 0.41 \\
\hline \multicolumn{4}{|l|}{$\begin{array}{l}\text { Co-interventions during study period } \\
\text { Insulin }\end{array}$} \\
\hline Use, $n(\%)$ & $19(82.6)$ & $22(46.8)$ & 0.004 \\
\hline Dose (units/day), median (Q1, Q3) & $18.9(3.8,37.5)$ & $0.0(0.0,14.9)$ & 0.003 \\
\hline Blood glucose (mmol/liter), median (Q1, Q3) & $9.5(7.6,11.9)$ & $7.7(6.5,10.3)$ & 0.05 \\
\hline \multicolumn{4}{|l|}{ Enteral formulae on day $1^{\dagger}, n(\%)$} \\
\hline Disease-non-specific & $8(34.8)$ & $27(57.5)$ & \\
\hline Disease-specific & $15(68.2)$ & $20(42.6)$ & 0.06 \\
\hline Propofol dose $(\mathrm{mcg} / \mathrm{kg} / \mathrm{min})$, median (Q1, Q3) & $1.2(0.0,9.0)$ & $5.2(1.4,11.2)$ & 0.06 \\
\hline \multicolumn{4}{|l|}{ Medications given during the ICU stay, $n(\%)$} \\
\hline Beta blockers & $10(43.5)$ & $23(48.9)$ & 0.67 \\
\hline Aspirin & $11(47.8)$ & $8(17.2)$ & 0.007 \\
\hline Angiotensin-converting enzyme inhibitors & $4(17.4)$ & $5(10.6)$ & 0.43 \\
\hline Angiotensin II receptor blockers & $1(4.4)$ & $0(0.0)$ & 0.15 \\
\hline Statins & $10(43.5)$ & $5(10.6)$ & 0.002 \\
\hline
\end{tabular}

${ }^{\dagger}$ Disease-non-specific formula: Osmolite, Jevity, Promote, Ensure plus, Resource, Ensure, Resource plus, Jevity (1.2); Disease-specific formula: Glucerna, Nutric hepatic, Nepro, Pulmocare, Novasource Renal, Peptamen (1.0), Peptamen (1.2), Suplena, Oxepa. Q1: first quartile, Q3: third quartile. ICU: intensive care unit. 


\subsection{Predictors of High FFA and FFA Levels During the Study Period}

On multivariable logistic regression analysis, the independent predictors of high FFAs level were diabetes (aOR, 5.36; 95\% CI, 1.56, 18.43; $p=0.008)$, and baseline cholesterol (aOR, 4.29; 95\% CI, 1.64, 11.19; $p=0.003$ ). Figure 1, panel A shows the serial levels of FFAs for patients with high FFAs and normal FFAs. Figure 1, panel B shows FFAs level in patients who received permissive underfeeding and standard feeding. The FFAs level was not different between the two feeding strategies.

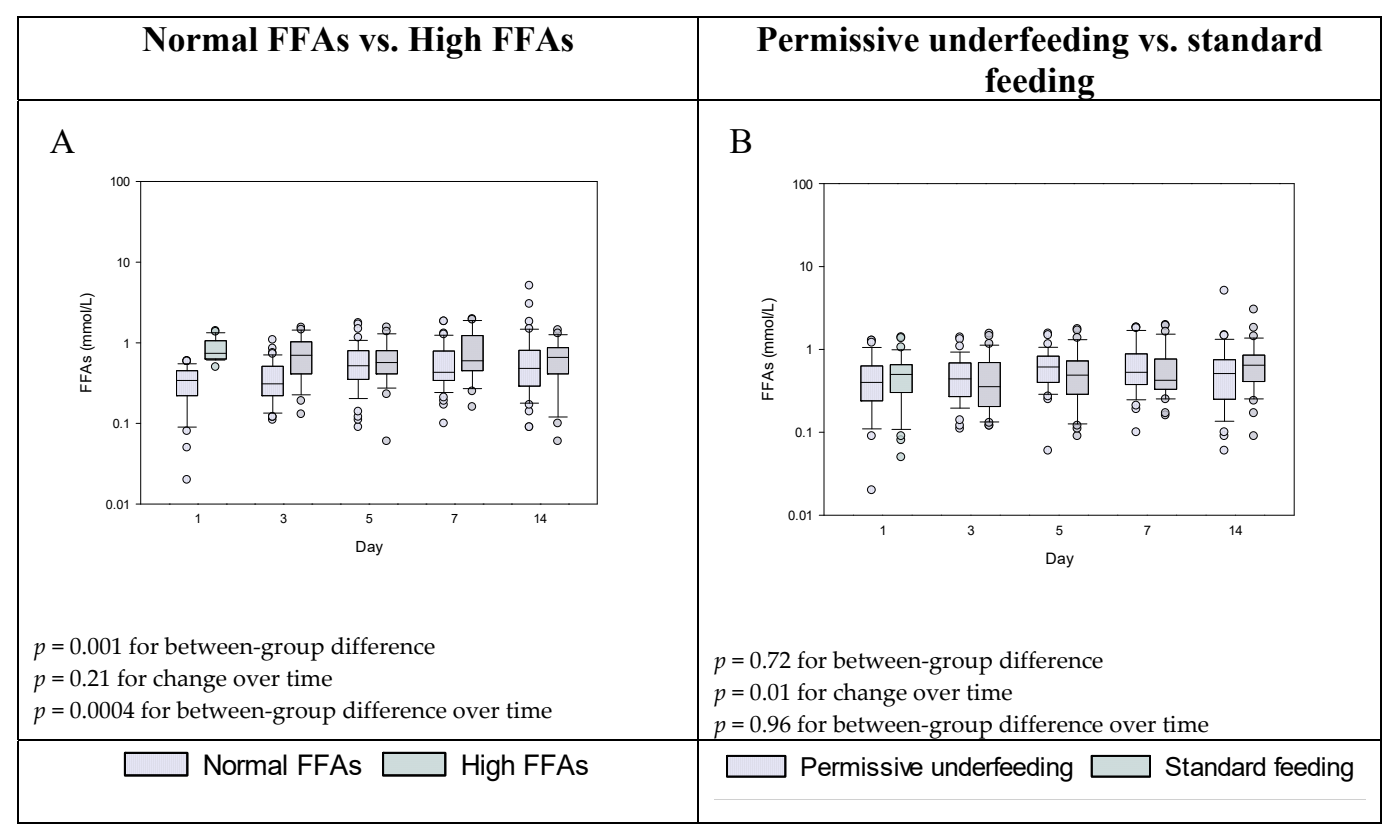

Figure 1. Serial levels of FFAs in patients with high and normal FFAs (Panel A) and in patients who received permissive underfeeding and standard feeding (Panel B). $p$ values for between-group differences and between-group differences over time are provided using mixed linear model.

\subsection{Outcomes of Patients}

There was no significant difference in crude mortality between patients with high and normal FFAs level (Table 3). Incident of renal replacement therapy was more frequent in patients with high FFAs level $(6 / 23(27.3 \%)$ compared to $2 / 47(4.7 \%), p=0.009)$. Multiple variable analyses adjusting for age, gender, BMI, APACHE II, diabetes, triglycerides, LDL cholesterol, HDL cholesterol, non-HDL cholesterol, and medical admissions (vs. non-medical admissions) showed no significant association between high FFAs level and 90-day mortality (aOR 0.49, 95\% CI 0.09, 2.60, $p=0.40$ ) or any other study outcomes (Table 3). 
Table 3. Outcomes of patients with high and normal free fatty acids (FFAs) level.

\begin{tabular}{|c|c|c|c|c|c|}
\hline Outcomes & $\begin{array}{l}\text { High FFAs Level } \\
\qquad n=23\end{array}$ & $\begin{array}{c}\text { Normal FFAs Level } \\
\qquad n=47\end{array}$ & Crude $p$ Value & Adjusted OR ** $(95 \% \mathrm{CI})$ & $p$ Value \\
\hline Death by 28 days, $n(\%)$ & $5(21.7)$ & $4(8.5)$ & 0.12 & $1.8(0.29,11.25)$ & 0.52 \\
\hline Death by 90 days, $n(\%)$ & $5(21.7)$ & $8(17.0)$ & 0.60 & $0.49(0.09,2.60)$ & 0.40 \\
\hline Death by 180 days, $n(\%)$ & $5(21.7)$ & $8(17.4)$ & 0.66 & $0.49(0.09,2.60)$ & 0.40 \\
\hline Death in the ICU, $n(\%)$ & $3(13.6)$ & $2(4.3)$ & 0.18 & $3.67(0.56,23.80)$ & 0.17 \\
\hline Death in the hospital, $n(\%)$ & $5(22.7)$ & $6(13.3)$ & 0.35 & $1.42(0.31,6.54)$ & 0.65 \\
\hline New renal replacement therapy, $n(\%)$ & $6(27.3)$ & $2(4.7)$ & 0.009 & $4.41(0.56,34.7)$ & 0.16 \\
\hline Healthcare-associated infections, $n(\%)$ & $12(52.2)$ & $27(57.5)$ & 0.68 & $0.62(0.21,1.86)$ & 0.40 \\
\hline Urinary tract infection, $n(\%)$ & $4(17.4)$ & $6(12.8)$ & 0.60 & $0.33(0.03,3.97)$ & 0.38 \\
\hline \multirow[t]{2}{*}{ Ventilator associated pneumonia, $n(\%)$} & $7(30.4)$ & $19(40.4)$ & 0.42 & $0.63(0.16,2.46)$ & 0.50 \\
\hline & & & & Parameter estimate $(95 \% \mathrm{CI})$ & \\
\hline ICU length of stay (days), median (Q1, Q3) & $15(11,22)$ & $17(11,24)$ & 0.45 & $-0.80(-6.42,4.81)$ & 0.76 \\
\hline Hospital length of stay (days), median (Q1, Q3) & $39(23,62)$ & $46.5(28.0,97.0)$ & 0.33 & $6.28(-27.74,40.3)$ & 0.71 \\
\hline $\begin{array}{l}\text { Duration of mechanical ventilation (days), } \\
\text { median }(\mathrm{Q} 1, \mathrm{Q} 3)\end{array}$ & $10(7,18)$ & $12(7,21)$ & 0.57 & $3.69(-2.05,9.43)$ & 0.20 \\
\hline ICU-free days, median $(\mathrm{Q} 1, \mathrm{Q} 3)$ & $74(54,79)$ & $72(55,78)$ & 0.73 & $5.73(-9.08,20.54)$ & 0.44 \\
\hline RRT-free days, median (Q1, Q3) & $14(8,14)$ & $14(14,14)$ & 0.01 & $-0.33(-2.40,1.73)$ & 0.75 \\
\hline MV-free days, median (Q1, Q3) & $12(7,21)$ & $10(7,18)$ & 0.51 & $4.70(-11.00,20.41)$ & 0.55 \\
\hline
\end{tabular}

ICU: intensive care unit, MV: mechanical ventilation, RRT: renal replacement therapy, Q1: first quartile, Q3: third quartile. ${ }^{* *}$ Adjusted for age, gender, BMI, APACHE II, diabetes, triglycerides, LDL cholesterol, HDL cholesterol, non-HDL cholesterol and medical admissions (vs. non-medical admissions). 


\section{Discussion}

In this study, we evaluated serum FFAs level in critically ill patients. We found that FFAs level was elevated at baseline in $32 \%$ of patients, and that it was associated with features of the metabolic syndrome. FFAs level was not affected by permissive underfeeding versus standard feeding. High FFAs level appear to be largely a reflection of the underlying metabolic condition of the patient rather than the critical illness itself.

Our study provides a characterization of critically ill patients with high FFAs level. We found that high FFAs level correlated highly with other lipid profile parameters (total, HDL and LDL cholesterol, but not triglycerides) and with age. Compared to those with normal FFAs level, patients with high FFAs level were at baseline significantly older, more likely to be diabetic, had higher HgbA1c, blood glucose, creatinine and non-HDL and LDL cholesterol concentrations, and had more hypoxemia (as reflected lower $\mathrm{pO}$ : $\mathrm{FiO} 2$ ratio) despite lack of differences in APACHE II scores, SOFA scores, and vasopressor demands. During ICU stay, patients with high FFAs level had increased demand for insulin, disease-specific nutrition therapy, RRT, aspirin, and statins. The differences suggest the association of high FFAs level with metabolic syndrome. There was no difference in BMI, between the two groups; however, BMI is known to have its limitations in predicting obesity [22]. Because of these differences, we carried out multivariable analyses to account for the confounding effect of some of these variables on clinical outcomes. These analyses show that high FFAs level is not associated independently with clinical outcomes. Interestingly, patients with high FFAs level had less 24-h urinary nitrogen excretion and less negative nitrogen balance. This may be related to lower muscle mass in this older population and more frequent insulin therapy.

Normally, FFAs are elevated during fasting and exercise, and their level drops postprandially after carbohydrate-rich meals. FFAs level are elevated in obesity and diabetes [1,3]. In acute critical illness, where lipolysis increases, serum FFAs level increases [6]. Our study demonstrated that one-third of critically ill patients had high FFAs level; most (63.6\%) of these patients were diabetics. We found that baseline cholesterol level and diabetes were independent risk factors for high FFAs level on multivariable logistic regression analysis. The effect of propofol on FFAs level is uncertain. In an experiment on dogs undergoing general anesthesia, high concentration of propofol (200 and $400 \mathrm{mcg} / \mathrm{kg} / \mathrm{min}$ ) were associated with increased FFAs level, although a study in humans undergoing general anesthesia for cardiopulmonary bypass showed that propofol $(50 \mathrm{mcg} / \mathrm{kg} / \mathrm{min})$ compared to midazolam did not alter serum FFAs level $[23,24]$. In our study, categorization of patients into high and low FFAs level was based on baseline serum specimens, and doses of propofol preceding enrolment were not collected. Our study was not designed to specifically address the effect of propofol on FFAs level. Nevertheless, the doses of propofol that were used during the ICU stay were on average much lower than what was used in these studies, and, therefore, the effect of propofol on FFAs level in our cohort is likely to be small. The slightly lower dose of propofol given to patients with high-FFAs level was likely to be related to being older and more susceptible to sedation. Therefore, these patients would normally receive smaller doses of propofol.

In addition to being a fuel source, FFAs have multiple other physiologic effects. FFAs are associated with insulin resistance and impaired glucose metabolism by inhibiting glucose oxidation and by stimulating protein kinase $C[1,10,25]$. They may also stimulate the autophagy of pancreatic beta cells [26]. In our study, patients with high FFAs level had higher blood glucose and required more insulin therapy during the ICU stay even though the baseline blood glucose level was similar in patients with high and normal FFAs, suggesting an association of FFAs and insulin resistance in ICU patients.

FFAs may also affect the course of acute critical illness. FFAs were found to exacerbate hyperglycemia-induced Toll-like receptor expression and activity in monocytic cells, increase superoxide release, enhance Nuclear factor- $\mathrm{kB}$ activity, and induce the release of proinflammatory factors in diabetics [27]. Whether FFAs affect inflammation in critically ill patients is less clear. In a porcine endotoxemia model, infusing lipids at two different concentrations was associated with no 
differences in plasma tumor necrosis factor- $\alpha$, interleukin6, and leucocytes between animals with low and high FFAs suggesting that FFAs does not play a significant pro-inflammatory mediator effect [28]. However, FFAs have been implicated in the pathogenesis of acute respiratory distress syndrome and has been identified as a prognostic factor for this syndrome. In a lipopolysaccharide-induced acute lung injury model, a 15-fold increase in free oleic acid was observed in bronchoalveolar lavage fluid from mice $8 \mathrm{~h}$ after lipopolysaccharide application [20]. The FFA, oleic acid has been demonstrated to be elevated in patients with ARDS (acute respiratory distress syndrome) and in patients at-risk for ARDS [11,29]. Patients with sepsis demonstrated a six-fold increase in plasma oleic acid levels compared to healthy volunteers [19]. In addition, FFAs are elevated in the blood of patients with sepsis who are at increased risk for ARDS [30]. The exact mechanism of FFAs-associated lung injury is unclear; however, FFAs have been shown to increase permeability and to impair transepithelial active sodium transport mechanisms in the lung, and could, thus, promote alveolar edema formation and prevent edema resolution [31]. In our study, where almost all patients were on mechanical ventilation at baseline, hypoxemia was more significant in patients with high FFAs compared with patients with normal FFAs (median PaO2: FiO2 ratio was 115 vs. 200, $p=0.02$ ), a finding that may be in line with the association of FFAs and lung injury. Whether FFAs are toxic to the kidneys is unclear. In an animal study, FFAs led to severe tubulointerstitial damage [32]. FFAs and their metabolites have been implicated in renal cell injury and development of chronic kidney in patients with the metabolic syndrome [33]. In our study, patients with high FFAs had a higher rate of new renal replacement therapy, although this association became not significant in multivariable analysis. This finding suggests that the observed crude association may be related to other confounders that put these patients at a higher risk for acute kidney injury; for example, patients with high FFAs level were more likely to be diabetics and had higher baseline creatinine compared to patients with normal FFAs level.

Weight loss leads to a lowering of FFAs level in the long run and can attenuate FFAs-induced hepatic insulin resistance in obese healthy patients [14-16]. However, the effects of short-term caloric restriction are different. In one study, 11 subjects were fed for two periods of 6 days with hypo- and eucaloric diet with the same macronutrient composition in random order [34]. At 6 days, fasting FFAs significantly increased with the hypocaloric diet compared with the eucaloric diet [34]. Whether the macronutrient composition affects FFAs was investigated in an animal model, and the study found that energy-restricted high-fat versus low-fat diet did not result in different FFA levels [35]. In the current study, serial levels of FFAs did not differ with time between patients receiving permissive underfeeding and standard feeding.

The study results should be interpreted taking into considerations its strengths and limitations. Strength include that data came from a randomized controlled trial, and that serial measurements of FFAs were obtained. The limitations include the sample size, which makes the study underpowered to detect a mortality difference. We measured total FFAs but not individual levels of each FFAs. In addition, the study included patients who had an expected duration of ICU stay $\geq 14$ days and, thus, the results may not be generalizable to patients who have a shorter stay.

In conclusion, we found that serum FFAs level was elevated in almost one-third of critically ill patients. High FFAs level was associated with features of the metabolic syndrome and was not affected by short-term moderate caloric restriction.

Supplementary Materials: The following are available online at http:/ /www.mdpi.com/2072-6643/11/2/384/s1, Table S1: Pearson correlations among baseline free fatty acids (FFAs) level and other related measures of lipid metabolism, Figure S1: Flow diagram for patients enrolled in the sub-study of free fatty acids (FFAs) level.

Author Contributions: Y.M.A.: conception, acquisition of data, design, analytical plan, drafting of the manuscript and critical revision of the manuscript for important intellectual content, approval of the final version to be published. W.T., G.J., D.J., H.M.A.-D., Musharaf Sadat, L.A., Maram Sakhija and A.A.-D.: acquisition of data, and critical revision of the manuscript for important intellectual content, approval of the final version to be published. H.T.: statistical analysis and critical revision of the manuscript for important intellectual content, approval of the final version to be published. 
Funding: The authors gratefully acknowledge the financial support from King Abdulaziz City for Science and Technology (KACST), Riyadh, Saudi Arabia under Grant Number-AT 32-25 KACST.

Acknowledgments: We wish to thank the following those who made valuable suggestions or who have otherwise contributed to the preparation of the manuscript: Maram Sakhija, Turki Almoammar, Muhammad Rafique Sohail, Shihab Mundekkadan and Aeron Toledo.

Conflicts of Interest: The authors declare that they have no competing interests.

\section{Abbreviations}

FFA Free Fatty Acid

APACHE Acute Physiology and Chronic Health Evaluation Scores

SOFA Sequential Organ Failure Assessment

ICU Intensive care unit

LOS Length of stay

aOR Adjusted odds ratio

\section{References}

1. Boden, G. Obesity, insulin resistance and free fatty acids. Curr. Opin. Endocrinol. Diabetes Obes. 2011, 18, 139. [CrossRef] [PubMed]

2. Tripathy, D.; Mohanty, P.; Dhindsa, S.; Syed, T.; Ghanim, H.; Aljada, A.; Dandona, P. Elevation of free fatty acids induces inflammation and impairs vascular reactivity in healthy subjects. Diabetes 2003, 52, 2882-2887. [CrossRef] [PubMed]

3. Lee, C.-H.; Olson, P.; Evans, R.M. Minireview: Lipid metabolism, metabolic diseases, and peroxisome proliferator-activated receptors. Endocrinology 2003, 144, 2201-2207. [CrossRef] [PubMed]

4. Jouven, X.; Charles, M.-A.; Desnos, M.; Ducimetière, P. Circulating nonesterified fatty acid level as a predictive risk factor for sudden death in the population. Circulation 2001, 104, 756-761. [CrossRef] [PubMed]

5. Preiser, J.-C.; Ichai, C.; Orban, J.-C.; Groeneveld, A.J. Metabolic response to the stress of critical illness. Br. J. Anaesth. 2014, 113, 945-954. [CrossRef] [PubMed]

6. Fong, Y.; Marano, M.A.; Moldawer, L.L.; Wei, H.; Calvano, S.E.; Kenney, J.S.; Allison, A.C.; Cerami, A.; Shires, G.T.; Lowry, S. The acute splanchnic and peripheral tissue metabolic response to endotoxin in humans. J. Clin. Investig. 1990, 85, 1896. [CrossRef] [PubMed]

7. Rosato, E.F.; Vemulapalli, P.; Lang, C.H.; Lanza-Jacoby, S. Insulin stimulates lipoprotein lipase activity and synthesis in adipocytes from septic rats. J. Surg. Res. 1997, 73, 73-79. [CrossRef]

8. Shi, S.; Gao, Y.; Wang, L.; Liu, J.; Yuan, Z.; Yu, M. Elevated free fatty acid level is a risk factor for early postoperative hypoxemia after on-pump coronary artery bypass grafting: Association with endothelial activation. J. Cardiothorac. Surg. 2015, 10, 122. [CrossRef]

9. Rockenfeller, P.; Ring, J.; Muschett, V.; Beranek, A.; Büttner, S.; Carmona-Gutierrez, D.; Eisenberg, T.; Khoury, C.; Rechberger, G.; Kohlwein, S.D.; et al. Fatty acids trigger mitochondrion-dependent necrosis. Cell Cycle 2010, 9, 2908-2914. [CrossRef]

10. Eftimiadi, C.; Buzzi, E.; Tonetti, M.; Buffa, P.; Buffa, D.; Van Steenbergen, M.; De Graaff, J.; Botta, G.A. Short-chain fatty acids produced by anaerobic bacteria alter the physiological responses of human neutrophils to chemotactic peptide. J. Infect. 1987, 14, 43-53. [CrossRef]

11. Bursten, S.L.; Federighi, D.A.; Parsons, P.; Harris, W.E.; Abraham, E.; Moore Jr, E.E.; Moore, F.A.; Bianco, J.A.; Singer, J.W.; Repine, J.E. An increase in serum C18 unsaturated free fatty acids as a predictor of the development of acute respiratory distress syndrome. Crit. Care Med. 1996, 24, 1129-1136. [CrossRef]

12. Sztefko, K.; Panek, J. Serum free fatty acid concentration in patients with acute pancreatitis. Pancreatology 2001, 1, 230-236. [CrossRef] [PubMed]

13. Karpe, F.; Dickmann, J.R.; Frayn, K.N. Fatty acids, obesity, and insulin resistance: Time for a reevaluation. Diabetes 2011, 60, 2441-2449. [CrossRef] [PubMed]

14. Chearskul, S.; Delbridge, E.; Shulkes, A.; Proietto, J.; Kriketos, A. Effect of weight loss and ketosis on postprandial cholecystokinin and free fatty acid concentrations. Am. J. Clin. Nutr. 2008, 87, 1238-1246. [CrossRef] [PubMed] 
15. Solomon, T.P.; Haus, J.M.; Marchetti, C.M.; Stanley, W.C.; Kirwan, J.P. Effects of exercise training and diet on lipid kinetics during free fatty acid-induced insulin resistance in older obese humans with impaired glucose tolerance. Am. J. Physiol. Endocrinol. Metab. 2009, 297, E552-E559. [CrossRef] [PubMed]

16. Haus, J.M.; Solomon, T.P.; Marchetti, C.M.; Edmison, J.M.; González, F.; Kirwan, J.P. Free fatty acid-induced hepatic insulin resistance is attenuated following lifestyle intervention in obese individuals with impaired glucose tolerance. J. Clin. Endocrinol. Metab. 2010, 95, 323-327. [CrossRef] [PubMed]

17. Arabi, Y.M.; Aldawood, A.S.; Haddad, S.H.; Al-Dorzi, H.M.; Tamim, H.M.; Jones, G.; Mehta, S.; Mclntyre, L.; Solaiman, O.; Sakkijha, M.H.; et al. Permissive underfeeding or standard enteral feeding in critically Ill adults. N. Engl. J. Med. 2015, 372, 2398-2408. [CrossRef] [PubMed]

18. Package Insert Ref ACS-ACOD Method EN 0318D5. Fujifilm WAKO Chemicals Europe GmbH: Neuss, Germany. Available online: https://www.wako-chemicals.de/files/download/pdf/nefa_standard_en_de_ 0718_web.pdf (accessed on 3 September 2018).

19. Knaus, W.A.; Draper, E.A.; Wagner, D.P.; Zimmerman, J.E. APACHE II: A severity of disease classification system. Crit. Care Med. 1985, 13, 818-829. [CrossRef]

20. Vincent, J.L.; de Mendonca, A.; Cantraine, F.; Moreno, R.; Takala, J.; Suter, P.M.; Sprung, C.L.; Colardyn, F.; Blecher, S. Use of the SOFA score to assess the incidence of organ dysfunction/failure in intensive care units: Results of a multicenter, prospective study. Working group on "sepsis-related problems" of the European Society of Intensive Care Medicine. Crit. Care Med. 1998, 26, 1793-1800. [CrossRef]

21. Joob, B.; Wiwanitkit, V. Middle East respiratory syndrome coronavirus infection: A short note on cases with renal failure problem. Ren. Fail. 2016, 38, 1749-1750. [CrossRef]

22. Adab, P.; Pallan, M.; Whincup, P.H. Is BMI the best measure of obesity? BMJ 2018, 360, k1274. [CrossRef] [PubMed]

23. Maeda, K.; Iwasaki, M.; Itou, Y.; Iwai, S.; Okano, S. Effect of propofol continuous-rate infusion on intravenous glucose tolerance test in dogs. Vet. Sci. 2018, 5, 43. [CrossRef] [PubMed]

24. Inoue, S.; Takauchi, Y.; Kayamori, Y.; Kuro, M.; Furuya, H. Propofol as a continuous infusion during cardiopulmonary bypass does not affect changes in serum free fatty acids. Eur. J. Anaesthesiol. 2001, 18, 113-117. [CrossRef] [PubMed]

25. Stefan, N.; Stumvoll, M.; Bogardus, C.; Tataranni, P.A. Elevated plasma nonesterified fatty acids are associated with deterioration of acute insulin response in IGT but not NGT. Am. J. Physiol. Endocrinol. Metab. 2003, 284, E1156-E1161. [CrossRef] [PubMed]

26. Komiya, K.; Uchida, T.; Ueno, T.; Koike, M.; Abe, H.; Hirose, T.; Kawamori, R.; Uchiyama, Y.; Kominami, E.; Fujitani, Y.; et al. Free fatty acids stimulate autophagy in pancreatic $\beta$-cells via JNK pathway. Biochem. Biophys. Res. Commun. 2010, 401, 561-567. [CrossRef] [PubMed]

27. Dasu, M.R.; Jialal, I. Free fatty acids in the presence of high glucose amplify monocyte inflammation via Toll-like receptors. Am. J. Physiol. Endocrinol. Metab. 2010, 300, E145-E154. [CrossRef] [PubMed]

28. Buhl, M.; Gjedsted, J.; Granfeldt, A.; Larsen, P.Ø.; Chew, M.; Møller, N.; Tønnesen, E. Circulating free fatty acids do not contribute to the acute systemic inflammatory response. an experimental study in porcine endotoxaemia. Basic Clin. Pharmacol. Toxicolo. 2009, 105, 319-326. [CrossRef] [PubMed]

29. Quinlan, G.J.; Lamb, N.J.; Evans, T.W.; Gutteridge, J.M. Plasma fatty acid changes and increased lipid peroxidation in patients with adult respiratory distress syndrome. Crit. Care Med. 1996, 24, 241-246. [CrossRef]

30. Mayer, K.; Gokorsch, S.; Fegbeutel, C.; Hattar, K.; Rosseau, S.; Walmrath, D.; Seeger, W.; Grimminger, F. Parenteral nutrition with fish oil modulates cytokine response in patients with sepsis. Am. J. Respir. Crit. Care Med. 2003, 167, 1321-1328. [CrossRef] [PubMed]

31. Vadasz, I.; Morty, R.E.; Kohstall, M.G.; Olschewski, A.; Grimminger, F.; Seeger, W.; Ghofrani, H.A. Oleic acid inhibits alveolar fluid reabsorption: A role in acute respiratory distress syndrome? Am. J. Respir. Crit. Care Med. 2005, 171, 469-479. [CrossRef]

32. Kamijo, A.; Kimura, K.; Sugaya, T.; Yamanouchi, M.; Hase, H.; Kaneko, T.; Hirata, Y.; Goto, A.; Fujita, T.; Omata, M. Urinary free fatty acids bound to albumin aggravate tubulointerstitial damage. Kidney Int. 2002, 62, 1628-1637. [CrossRef] [PubMed]

33. Nangaku, M. Mechanisms of tubulointerstitial injury in the kidney: Final common pathways to end-stage renal failure. Intern. Med. 2004, 43, 9-17. [CrossRef] [PubMed] 
34. Seevaratnam, N.; Bennett, A.; Webber, J.; Macdonald, I. The effects of underfeeding on whole-body carbohydrate partitioning, thermogenesis and uncoupling protein 3 expression in human skeletal muscle. Diabetes Obes. Metab. 2007, 9, 669-678. [CrossRef] [PubMed]

35. Kalupahana, N.S.; Voy, B.H.; Saxton, A.M.; Moustaid-Moussa, N. Energy-restricted high-fat diets only partially improve markers of systemic and adipose tissue inflammation. Obesity 2011, 19, 245-254. [CrossRef] [PubMed]

(c) (C) 2019 by the authors. Licensee MDPI, Basel, Switzerland. This article is an open access article distributed under the terms and conditions of the Creative Commons Attribution (CC BY) license (http://creativecommons.org/licenses/by/4.0/). 